\title{
Snow conditions as an estimator of the breeding output in high-Arctic pink-footed geese Anser brachyrhynchus
}

\author{
Gitte Høj Jensen • Jesper Madsen • Fred A. Johnson • \\ Mikkel P. Tamstorf
}

Received: 29 January 2013/Revised: 14 August 2013/Accepted: 17 August 2013/Published online: 16 November 2013

(C) The Author(s) 2013. This article is published with open access at Springerlink.com

\begin{abstract}
The Svalbard-breeding population of pinkfooted geese Anser brachyrhynchus has increased during the last decades and is giving rise to agricultural conflicts along their migration route, as well as causing grazing impacts on tundra vegetation. An adaptive flyway management plan has been implemented, which will be based on predictive population models including environmental variables expected to affect goose population development, such as weather conditions on the breeding grounds. A local study in Svalbard showed that snow cover prior to egg laying is a crucial factor for the reproductive output of pink-footed geese, and MODIS satellite images provided a useful estimator of snow cover. In this study, we up-scaled the analysis to the population level by examining various measures of snow conditions and compared them with the overall breeding success of the population as indexed by the proportion of juveniles in the autumn population. As explanatory variables, we explored MODIS images, satellite-based radar measures of onset of snow melt, winter NAO index, and the May temperature sum and May thaw
\end{abstract}

Electronic supplementary material The online version of this article (doi:10.1007/s00300-013-1404-7) contains supplementary material, which is available to authorized users.

G. H. Jensen $(\bowtie) \cdot$ M. P. Tamstorf

Department of Bioscience, Arctic Research Centre, Aarhus University, Frederiksborgvej 399, P.O. Box 358, 4000 Roskilde, Denmark

e-mail: ghje@dmu.dk

J. Madsen

Department of Bioscience, Arctic Research Centre, Aarhus University, C.F. Møllers Allé 8, 8000 Aarhus, Denmark

F. A. Johnson

Southeast Ecological Science Center, U.S. Geological Survey,

7920 NW 71st Street, Gainesville, FL 32653, USA days. To test for the presence of density dependence, we included the number of adults in the population. For 2000-2011, MODIS-derived snow cover (available since 2000) was the strongest indicator of breeding conditions. For 1981-2011, winter NAO and May thaw days had equal weight. Interestingly, there appears to have been a phase shift from density-dependent to density-independent reproduction, which is consistent with a hypothesis of released breeding potential due to the recent advancement of spring in Svalbard.

Keywords Breeding success - Density dependence · Adaptive management $\cdot$ Snow cover - Winter NAO . MODIS · Pink-footed goose $\cdot$ Reproduction

\section{Introduction}

During the last several decades, widespread changes in the global climate and environment have been observed, with the Arctic having experienced more heat than any other region on Earth (AMAP 2011). Climate change is expected to result in a variety of biological responses in Arctic animal populations (ACIA 2005; Post et al. 2009; Gilg et al. 2012). Responses range from direct effects like loss of sea ice habitat, or loss of snow cover on potential nesting grounds for birds, to indirect effects like advanced snow melt resulting in earlier plant growth or drying of habitats. In the short term, such changes may have negative or positive effects on organisms at higher trophic levels depending on their eco-physiological or behavioral ability to adjust their timing of emergence, migration, or reproduction. On the negative side, trophic mismatches between available resources and the timing of reproduction have been suggested in caribou Rangifer tarandus (Post et al. 
2008) and snow geese Anser caerulescens (Dickey et al. 2008), resulting in reduced productivity and survival of offspring. On the positive side, early snow melt and reduced snow cover may be beneficial for animal populations where snow or frost limit the accessibility to food resources or nesting grounds. Additionally, warming may lead to higher productivity of food resources (Cadieux et al. 2008; Madsen et al. 2011).

In Arctic-breeding geese, the timing of breeding and reproductive success is highly variable and depend on a number of intrinsic and extrinsic factors, but perhaps, none is more important than the timely disappearance of snow and ice to allow for the initiation of nesting (Reeves et al. 1976; Owen and Norderhaug 1977; Prop and de Vries 1993; Strong and Trost 1994; Morrissette et al. 2010). Especially, in high-Arctic-breeding species, this is critical because of the short frost-free season. As an adaptation, high-Arctic-nesting pink-footed geese are capital breeders; they build up energy stores, copulate, and start follicular development on the spring staging areas in Norway prior to the final migration to Svalbard (Drent et al. 2003; Madsen and Klaassen unpubl. data). Therefore, when they arrive on the breeding grounds in Svalbard in the second or third week of May, they can, depending on the snow conditions, either begin egg laying almost right away (Glahder et al. 2006; Madsen et al. 2007) or wait until the nesting sites clear of snow. The delay can result in geese increasingly abandoning nesting efforts (Madsen et al. 2007). Furthermore, during prolonged snow cover, feeding opportunities are limited and geese have to rely on body reserves. As a consequence, late-nesting geese may lay smaller clutches and their offspring may have a lower survival (Lepage et al. 2000). In pink-footed geese, it is predicted that earlier snow melt due to climate change will lead to increased nest success (Madsen et al. 2007). In addition, a longer frost and snow-free season is predicted to increase the available habitat for breeding (Jensen et al. 2008).

The population of pink-footed geese has more than doubled in numbers since the 1990 s, reaching an unprecedented peak of 80,000 in autumn 2011. The recent increase seems at least partly due to improved breeding success (Madsen unpubl. data). As the population has increased, goose foraging on farmland has increased conflicts with agricultural interests on the wintering grounds in Belgium, the Netherlands, and Denmark, and especially in staging areas in Norway (Madsen and Williams 2012). In addition, there are signs of degradation of vulnerable tundra vegetation in Svalbard due to increasing grazing pressure by pinkfooted geese (Speed et al. 2009). Therefore, it has been agreed to develop an international flyway management plan under the auspices of the African-Eurasian Waterbird Agreement. The plan includes objectives to stabilize the population size by increasing the harvest of geese in the autumn (Madsen and Williams 2012). A population target for pink-footed geese has been agreed upon through an adaptive harvest-management framework (Nichols et al. 2007). The idea is to regulate harvest rates based on a suite of demographic models, which include a host of variables related to goose population development (Nichols et al. 2007). Since climate change is hypothesized to contribute to the growth of the population, it is important to identify reliable variables that can be used to predict the breeding output in advance of the hunting season and, hence, improve the reliability harvest-management decisions.

From 2003 to 2006, a study on a local scale was conducted to explore the applicability of snow cover estimates derived from satellite imagery as an explanatory variable of nesting phenology, numbers of nesting pairs, and breeding success. The results showed that MODIS satellite images were useful for estimating snow cover and that snow cover appeared to have a number of effects on local reproductive parameters (Madsen et al. 2007). An extension of the study to 2010-2012 showed that the local population had more than doubled, from 49 nests in 2005 to 226 nests in 2010. However, annual numbers of breeding geese were still reduced in years with extended spring snow cover (Anderson et al. submitted).

In this study, we up-scale the analysis to the population level by examining various measures of snow conditions and spring temperatures and compared them with the overall breeding success of the population recorded as indexed by the proportion of juveniles in the autumn population. We explored MODIS images from a longer time series and combined for several nesting sites, microwave backscatter as a measure of onset of snow melt, the May temperature sum and number of days with temperatures above the freezing point (as a proxy of the degree of snow melt), and winter North Atlantic Oscillation (NAO) as explanatory variables. In addition, we included observed adult population size in the previous autumn to test for density dependence in reproductive output. Our hypothesis was that overall productivity will be lower in years with a late onset of snow melt, high degree of snow cover, and/or low temperature sum and number of thaw days in May. Our aim was to find a general predictor for the reproductive output of the Svalbard population of pink-footed geese, which can be included in population models as part of the adaptive harvest-management framework.

\section{Materials and methods}

\section{Study population}

The Svalbard population of pink-footed geese mainly breeds in lowland valleys, coastal plains, and under bird 


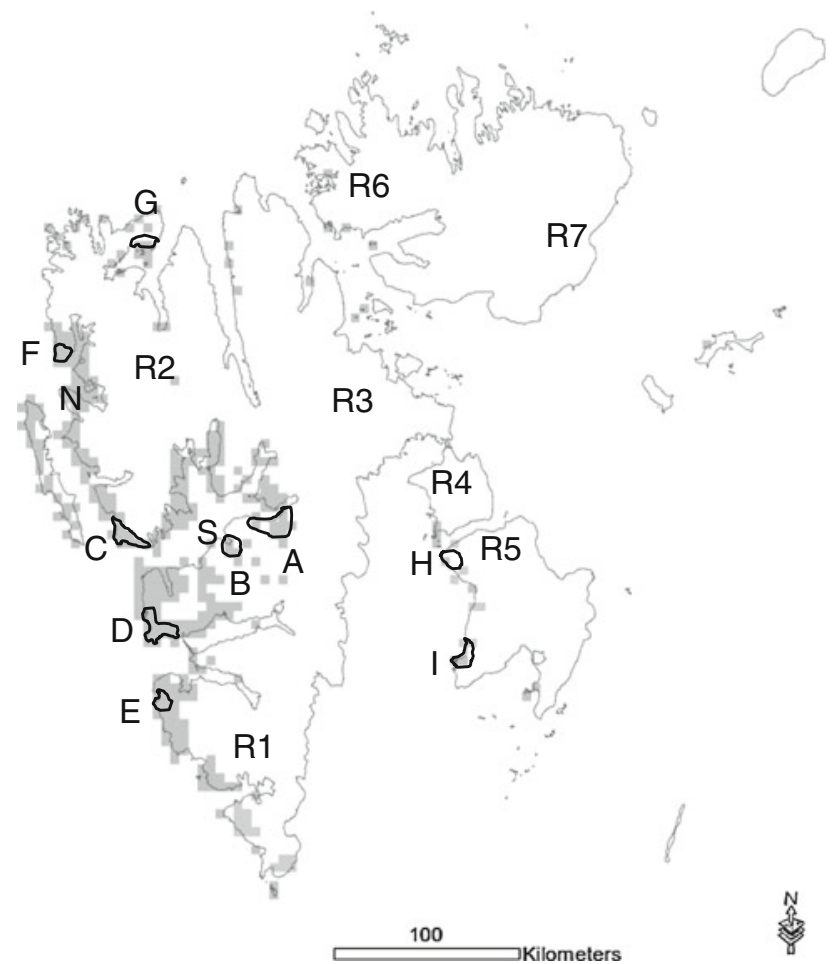

Fig. 1 Pink-footed goose nesting distribution in Svalbard and the nine areas selected for analysis of snow cover: $A$ Sassendalen, $B$ Adventdalen, $C$ Daudmanns $\varnothing y r a, D$ Nordenskiöldkysten, $E$ Dunderbukta, $F$ Bohemiaflya, $G$ Reinsdyrflya, $H$ Rosenbergdalen, and I Grunlinnesletta. Dark grey colors refer to confirmed nesting areas; light grey to probable nesting areas $(5 \times 5 \mathrm{~km}$ grid resolution) (from http://goosemap.nina.no). $R 1-R 7$ refer to the regions used in the analysis of snow melt onset (from Rotschky et al. 2011). The meteorological stations Svalbard Airport and Ny-Ålesund are indicated by and $\mathrm{S}$ and $\mathrm{N}$, respectively

cliffs in the central part of the main island of Spitsbergen (Fig. 1; http://goosemap.nina.no). After arrival, the first eggs are laid from May 20 to June 14 (Madsen et al. 2007). This is followed by a 26- to 27-day incubation period and an eight-week fledging period (Owen 1980). The pinkfooted geese prefer nesting in close vicinity to feeding patches such as wet moss vegetation. Nests are mainly found in patches of Dryas heath vegetation on south-facing slopes with intermediate grade and intermediate elevation (Wisz et al. 2008).

The Svalbard population winters in Denmark, the Netherlands, and Belgium and migrates northward via staging areas in Denmark, Nord-Trøndelag in mid Norway, and Vesterålen in north Norway. Furthermore, the geese stop at pre-nesting areas in west Spitsbergen before finally arriving at the nesting sites (Glahder et al. 2006). In late June, nonbreeding geese or failed breeders undertake a molt migration from the western to the eastern and northern parts of Svalbard (Glahder et al. 2007).
Population productivity and population size

In assessing the influence of May snow conditions on population productivity, the proportion of juveniles in the following autumn population is used. The proportion of juveniles in the population and brood sizes have been assessed annually since 1980 on the staging grounds in Denmark and the Netherlands during September-October (Ganter and Madsen 2001). At this time, it is possible to distinguish between juveniles $(<1 / 2$ year) and those older (1.5-year-old immatures plus $\geq 2.5$-year-old potential breeders) by plumage characteristics (Patterson and Hearn 2006).

In early November each year, the size of the pink-footed goose population is estimated by ground counts over the entire nonbreeding range from Trøndelag in mid Norway, to Denmark, the Netherlands, and Belgium. Counts are made by experienced teams of goose counters and on fixed days to prevent double counts. In recent years, counts have been performed in spring as well.

Density-dependent effects

In addition to searching for climatic predictors for reproductive output of pink-footed geese, we looked for presence of density dependence in the population by including the observed adult population in the previous year. The adult population in this paper consists of both 1.5 -year-old immatures and $\geq 2.5$-year-old potential breeders, since the autumn populations counts only allow us to partition juveniles $(<1 / 2$ year) and those older ( $\geq 1.5$ years). In the following spring, these will be aged 1.0 year and $\geq 2.0$ year. Based on neck-band observations, 2 -year birds have been observed with offspring (Madsen unpubl. data); therefore, we used the number of $\geq 1.5$-year olds in the autumn to index the potential number of breeders during the subsequent spring. We used the adult population rather than total population size as a measure of density because we believe it would better reflect potential competition for nesting sites in Svalbard. The number of adult birds was calculated from annual population estimates and age ratios.

Explanatory variables

\section{Snow cover}

To up-scale the previous study, we selected nine places in Svalbard, all known to be pink-footed goose breeding areas and covering the core breeding range of the population (Fig. 1; http://goosemap.nina.no). Six of the nesting areas are located in west Spitsbergen: A) Sassendalen $\left(17.00^{\circ} \mathrm{E}\right.$, $\left.78.20^{\circ} \mathrm{N}\right)$; B) Adventdalen $\left(16.00^{\circ} \mathrm{E}, 78.20^{\circ} \mathrm{N}\right)$; C) Daudmannsøyra $\left(13.08^{\circ} \mathrm{E}, 78.15^{\circ} \mathrm{N}\right)$; D) Nordenskiöldkysten 
$\left(13.45^{\circ} \mathrm{E}, 77.54^{\circ} \mathrm{N}\right)$; E) Dunderbukta $\left(13.58^{\circ} \mathrm{E}, 77.29^{\circ} \mathrm{N}\right)$; and F) Bohemiaflya $\left(12.04^{\circ} \mathrm{E}, 78.49^{\circ} \mathrm{N}\right)$; one site was selected to represent the northern part: G) Reinsdyrflya $\left(13.30^{\circ} \mathrm{E}, 79.47^{\circ} \mathrm{N}\right)$ and two on Edgeyøa, namely H) Rosenbergdalen $\left(21.50^{\circ} \mathrm{E}, 78.50^{\circ} \mathrm{N}\right)$ in the northwest and I) Grunlinnesletta $\left(22^{\circ} \mathrm{E}, 78^{\circ} \mathrm{N}\right)$ in the southwest.

The distribution of snow cover in the nine study areas was analyzed using MODIS satellite images with a resolution of $250 \mathrm{~m}$, since reliable snow depth data are not available. This was done to evaluate the snow cover conditions at the time of egg laying from 2000 to 2011. All images were geo-referenced using the MODIS Swath Reprojection Tool (https://lpdaac.usgs.gov/tools/modis_ reprojection_tool_swath). No atmospheric correction was performed. Due to cloud cover on many MODIS satellite images, the dates of imagery ranged from May 16 to June 4 , but as for the previous analysis, we found that the images were applicable to compare snow conditions from year to year. This is due to low temperature, minimum of precipitation, and generally late onset of melt. It was possible to get cloud-free images for the 12-year period for all nine areas with the exception of Dunderbukta (area E) in 2004 and Daudmannsøyra (area C) in 2009. Classification was done in accordance with Madsen et al. (2007).

\section{Summer melt onset}

Using images from the satellite QuikSCAT SIT, which are based on a SeaWind microwave scatterometer, it is possible to detect the onset of snow melt due to the pronounced backscatter contrast between dry and wet snow. Snow melt onset is defined as the point in time when microwave brightness temperatures increase sharply due to the presence of liquid water in the snowpack. Rotschky et al. (2011) used the methodology to identify the annual summer melt onset (SMO) in seven regions of Svalbard (Fig. 1; http://goosemap.nina.no) for the period 2000-2008, and we have used their estimates. Unfortunately, in November 2009, QuikSCAT failed and we are not aware of updated datasets based on a new sensor and that have been calibrated with QuikSCAT.

\section{Temperature sum and thaw days}

As a proxy for the strength of snow melt, we used (a) temperature sum, defined as the cumulative sum of average daily mean temperatures above $0{ }^{\circ} \mathrm{C}$ during May, and (b) thaw days, defined as the number of days in May with average daily mean temperature above $0{ }^{\circ} \mathrm{C}$. The mean daily temperature was derived from $\mathrm{Ny}$-Ålesund and Svalbard Airport meteorological stations (Fig. 1; http:// goosemap.nina.no; http://www.met.no).

\section{North Atlantic oscillation}

The large-scale climatic phenomenon NAO is largely an atmospheric mode. It controls the strength and direction of westerly winds and storm tracks across the North Atlantic, which induces variation in temperature and precipitation from central North America to Europe and into Northern Asia. NAO is based on the difference in normalized sealevel pressure between Lisbon (Portugal) and Stykkisholmur (Iceland) (Hurrell 1995). Annual fluctuations in the NAO/Arctic oscillation (AO) have been associated with interannual variability in onset of snow, snowmelt, and the number of snow-free days observed in the Northern Hemisphere (Bamzai 2003; Luks et al. 2011). High/positive $\mathrm{NAO} / \mathrm{AO}$ is associated with warm and wet winters in northern Europe, due to enhanced westerly flow, which moves mild moist air north-eastwards across the North Atlantic toward the eastern part of the Arctic. However, Svalbard is at the edge of the pressure system and does not follow the normal trend. Studies from Adventdalen (Tyler et al. 2008) and Hornsund (Luks et al. 2011) show that cold and dry winters in Svalbard are associated with high/ positive NAO/AO and vice versa. We adopt these results to get a more local measure of spring temperatures and snow conditions. In this study, we use the winter NAO index between December and March, which displays the greatest interannual and decadal variability (Hurrell 1995), and it is the index that has been associated with the observed longterm increase in the extratropical mean temperature of the Northern Hemisphere (Hurrell 1996).

\section{Statistical analysis}

All our metrics are related to snow conditions, and several of the areas investigated for each explanatory variable are located close to each other.

We therefore expected some degree of correlation between the explanatory variables and between the areas investigated for each explanatory variable. The presence of correlation was tested using Pearson's correlation coefficient. Whenever significant correlation was established between explanatory variables, only one variable was analyzed at a time, and when correlation was present between areas, an average of areas was taken.

Climate and goose population data ranged from 1981 to 2011. However, due to lack of data pre-2000 for the variables snow cover and SMO, the analysis of the variables as predictors for the proportion of juveniles was split into two periods: the complete period from 1981 to 2011 and a shorter period from 2000 to 2011. Further, since the Arctic has experienced more heat than any other region on Earth, we also looked for trends in predictors using locally 
weighted polynomial regression (Cleveland 1979) and by examining means pre- and post-2000.

The ability of different covariates to explain variation in the proportion of juveniles was assessed using maximum likelihood estimation. We used a generalized linear model with a logit-link function and examined both a binomial and beta-binomial distribution for the proportion of juveniles. Thus, to test the effect of environmental variable on the proportion of juveniles $\left(p_{\mathrm{t}}\right)$, we used a model of the form (Eq. 1):

$p_{t}=\frac{1}{\left(1+\exp \left(-\left(\beta_{0}+\beta_{1} X+\beta_{2} A\right)\right)\right)}$

where $X$ is either snow cover, SMO, winter NAO, May thaw days, or May temperature sum in the present year, $A$ is the adult population in the previous autumn, and $\beta$ are regression coefficients. For the period 2000-2011, all predictor variables were available, and we refer to the associated models as model set 1 . For model set 2 , we used available data from 1981-2011, which means that $X$ is limited to either winter NAO, May temperature sum, or May thaw days.

We assessed relative model utility using Akaike's information criterion (AIC) (Burnham and Anderson 2002). The model with the smallest AIC value was selected as providing the best description of the data. Model weights were also calculated based on AIC values, reflecting the relative weight of evidence in favor of the respective models from among all the candidate models. All analyses were performed using the $\mathrm{R}$ statistical program (http:// www.r-project.org).

\section{Results}

Snow cover

Snow cover in late May during 2000-2011 varied from $2 \%$ (area C, 2010) to $100 \%$ (area G, 2002, 2011). The northern areas had a higher percentage of snow cover than the southern areas, and the areas located inland and to the east had a lower snow cover than the coastal areas. On average, area $\mathrm{G}$ had the highest percentage snow cover (93.6\%), and area B had the lowest (64.9\%). Among years, 2010 had the lowest average percentage snow cover $(46.8 \%)$, and 2008 had the highest $(95.0 \%)$. For all areas, 2010 and 2006 (with the exception of 2010, area G) were below the average snow cover, and 2000 and 2008 were above.

Because we found snow cover between the nine areas used for snow cover classifications to be correlated ( $r=0.1023-0.9049, \bar{r}=0.4920, n=21)$, we used an average for subsequent analyses. The accuracy of snow classification did not fall below 97.5\%. Image acquisition dates are shown in Appendix of supplementary material

Summer melt onset

The annual SMO during 2000-2008 derived from Rotschky et al. (2011) had its earliest start on April 24 (region R5, 2006) and the latest on June 22 (region R6, 2000 and region $\mathrm{R} 7,2008)$. The northern and eastern regions had a later SMO than the southern and western regions. On average, the onset of snow melt was earliest in region R1 (May 28) and latest in region R6 (June 12). Among years, 2006 had the earliest SMO (May 14) and 2000 had the latest (June 18). Correlation was observed between regions for estimation of annual SMO $(r=0.4133-0.9773$, $\bar{r}=0.7916, n=21$ ), and an average was used in analyses.

Temperature sum and thaw days

In $\mathrm{Ny}$ - $\mathrm{\circ}$ lesund, the number of days in May with mean temperature above $0^{\circ}$ ranged from 0 days $(1996,1998$, and 2007) to 19 days (2010), with an average of 7 days. At Svalbard Airport, the May thaw days ranged from 0 days (1998) to 22 days (2010), with an average of 8 days. The number of May thaw days was lowest for the northern station Ny-Ålesund and highest for the inland station Svalbard Airport. May thaw days for the two weather stations were strongly correlated $(r=0.7482)$, and an average was used in analyses. Between periods, the average May thaw days during 2000-2011 nearly doubled compared to 1981-1999 (10 vs. 6 days). The locally

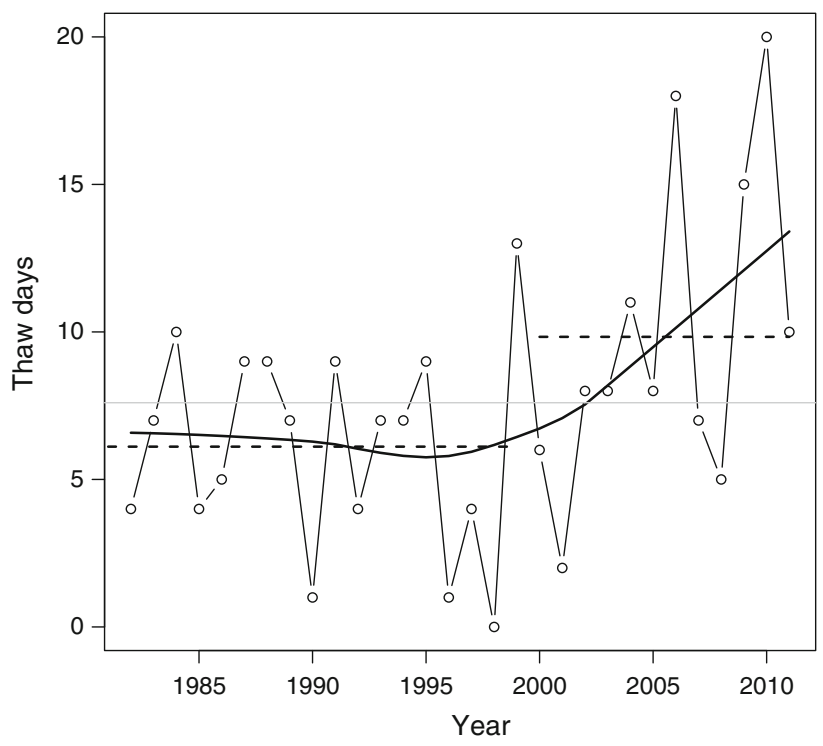

Fig. 2 Trend in average May thaw days from 1981-2011 (solid line), the overall mean (grey line), and the pre-2000 and post-2000 means (dashed lines) 
weighted regression was also suggestive of an increasing trend in May thaw days (Fig. 2).

In Ny-Ålesund, the May temperature sum ranged from 0 degree-days (1996, 1998, and 2007) to 36.5 degree-days (2006), with an average of 9.3 degree-days. At Svalbard Airport, May temperature sum ranged from 0 degree-days (1998) to 42.6 degree-days (2006), with an average of 10.6 degree-days. Correlation was observed between May temperature sum for the two weather stations $(r=0.7951)$, and an average was used in analyses.

In regards to trend in average May temperature sum between the two periods 1981-1999 and 2000-2011, we see the same tendency as for May thaw days. The latest period (2000-2011) had an average of 13.4 degree-days, whereas the earlier period (1981-1999) had 7.8 degreedays.

\section{North Atlantic oscillation}

From 1981-2011, the winter NAO ranged from 5.08 (1989) to -4.64 (2010), with an average of 0.91 . Ten years were associated with a negative NAO index, whereas 20 years were associated with positive NAO index. Investigating trends in winter NAO show that a large proportion of the negative values were in the period 2000-2011, with an index mean of -0.07 (warm and wet) compared to the period 1981-1999 with an index mean of 1.51 (cold and dry).

\section{Population parameters}

During 1981-2011, the proportion of juveniles in autumn ranged from 0.049 (2000) to 0.236 (1987 and 1995), with an average of 0.146 , and total autumn population estimates ranged from 21,000 (1981) to 80,000 (2011), with an average of 40,461 . The adult population ranged from 19,320 (1981) to 64,400 (2011), with an average of 34,637 (Fig. 3). The trend in proportion of juveniles seems to follow two directions: first a decrease until around 2000 and thereafter an increase (Fig. 4). The average proportion of juveniles for the first period (1981-1999) was 0.154 $( \pm 0.083, n=19)$, and for the second period, it was 0.128 $( \pm 0.096, n=12)$.

\section{Population productivity models}

To investigate the potential of a variety of environmental variables as predictors for proportion of juveniles $\left(p_{t}\right)$, the following four variables were selected: (1) average snow cover for areas with cloud-free images for the period 2000-2011 (areas A, B, D, F, G, H, and I); (2) winter NAO; (3) average May temperature sum; and (4) average May thaw days. Due to correlation among the average

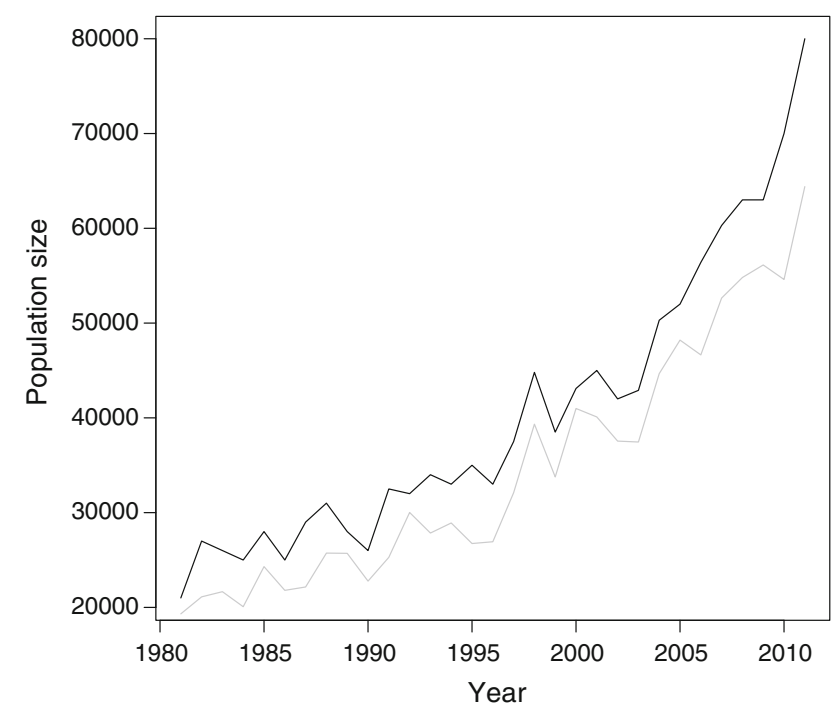

Fig. 3 Development of the size of the total Svalbard pink-footed goose population (solid line) and the adult population size (1.5-yearold immatures and $\geq 2.5$-year-old potential breeders) (grey line), 1981-2011

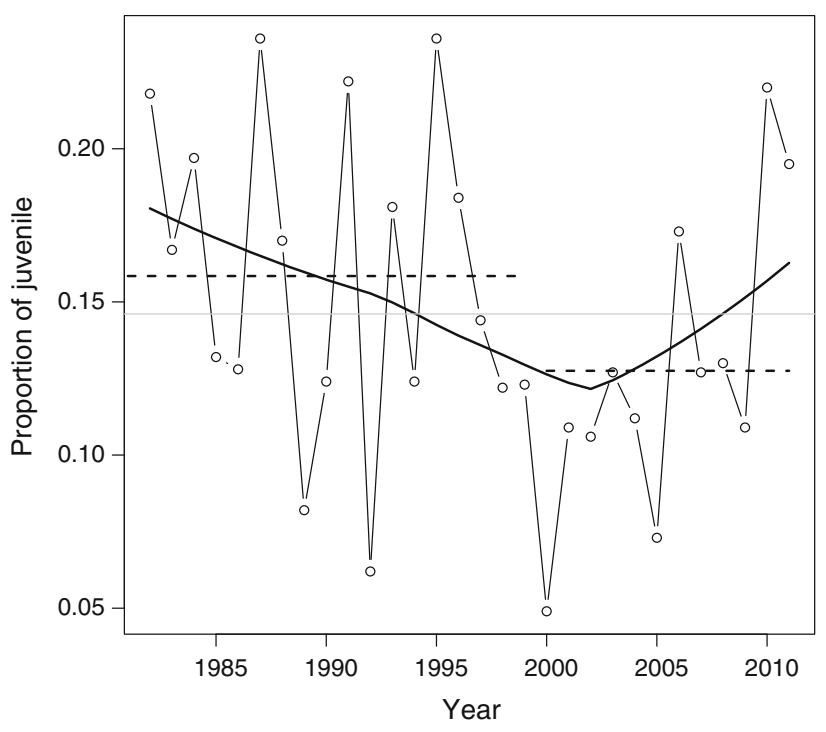

Fig. 4 Trend in proportion of juveniles from 1981-2011 (solid line), the overall mean (grey line), and the pre-2000 and post-2000 means (dashed lines)

explanatory variables (Fig. 5), only one variable was investigated at a time in the candidate models. We did not include SMO in the analysis due to the short time series and correlation with the other environmental variables (Fig. 5).

Given the set of candidate models for the period 20002011 (Table 1), the model using current snow cover and prior adult population (Eq. 2; Fig. 6a) had the lowest AIC value and the highest model weight (0.4404), compared to 


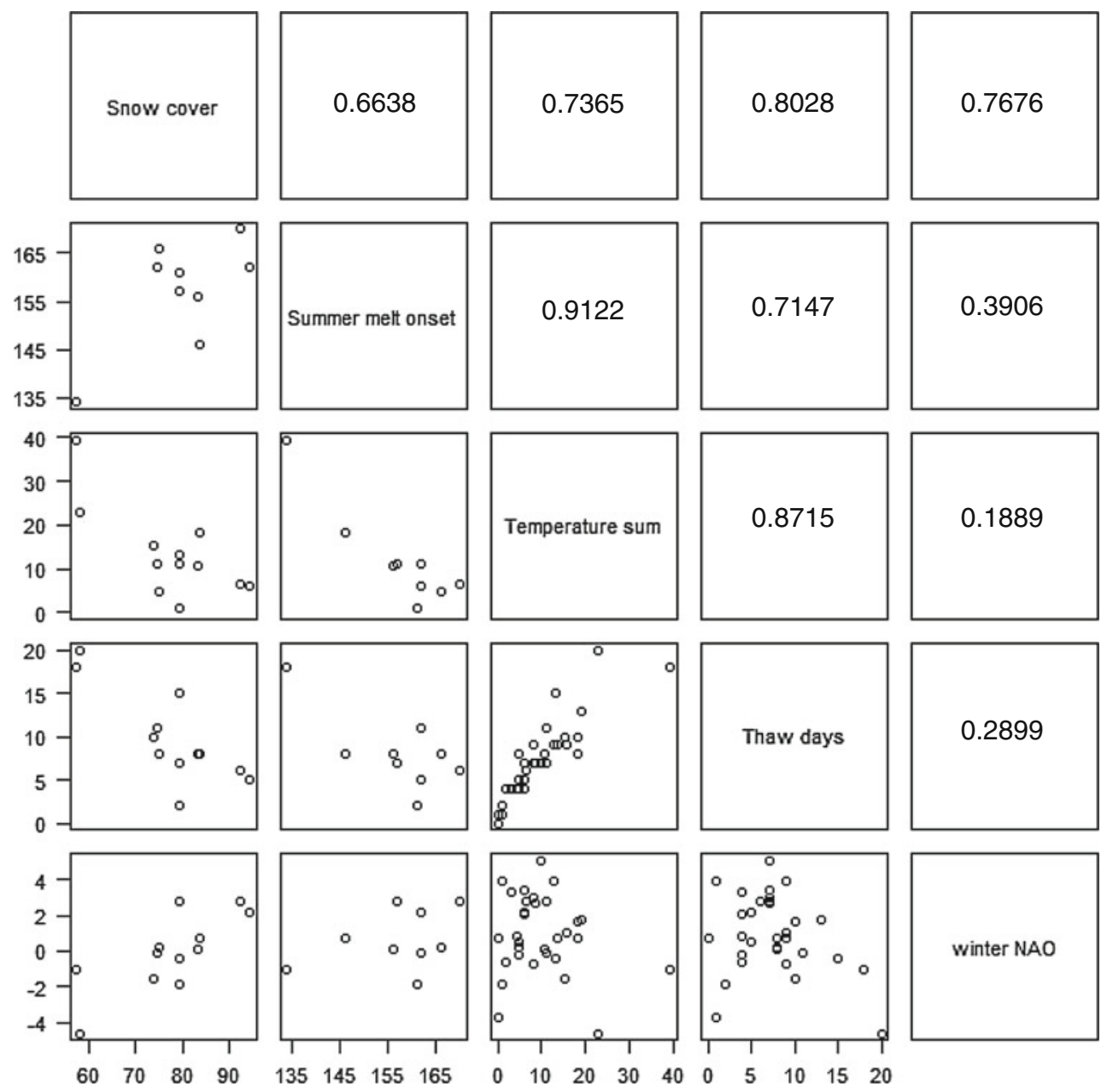

Fig. 5 Correlation between the environmental variables; average snow cover, average summer melt onset (Julian date), average May temperature sum $\left({ }^{\circ} \mathrm{C}\right)$, average number of May thaw days, and winter NAO index

the second best model, which only used snow cover (dAIC 2.2, weight 0.1462) (Table 2). Both models suggest an increase in snow cover results in a decrease in proportion of juveniles. Interestingly, the model that included prior adult population size is not negative density dependent, but rather the opposite. Thus, larger prior adult population is associated with a larger proportion of juveniles. However, there is no statistical evidence of a positive effect from adult population on the proportion of juveniles $\left(\beta_{\mathrm{z}}=0.0216,95 \% \mathrm{CI}-0.0025-0.0457\right)$. This tendency is independent of the climatic variable used in model set 1 . The best candidate model was $\left(R^{2}=0.7468, F_{2,9}=13.27\right.$, $p=0.0021)$ :
For the longer period, ranging from 1981 to 2011, three models showed equally low AIC values and almost equal model weight (Table 3): the density-dependent model using winter NAO index (weight 0.1791) (Eq. 3a; Fig. 6b), the density-independent model using winter NAO index (weight 0.1787) (Eq. 3b; Fig. 6c), and the density-dependent model using May thaw days (weight 0.1774) (Eq. 3c; Fig. 6d). In contrast to the models using data from 2000 to 2011 and previous adult population, all models from 1981 to 2011 that included previous adult population showed a negative density-dependent effect. However, there was no statistical evidence of a negative effect from adult population on the proportion of juveniles $\left(3 \mathrm{a} . \beta_{\mathrm{z}}=-0.0094\right.$,

1

$p_{t}=\frac{1}{\left(1+\exp \left(-\left(-1.5058-0.0216 \text { Snow }_{\text {cover }}+0.0268 A_{t-1}\right)\right)\right)}$ 
Table 1 Candidate models of the relationship between explanatory variables and the production of juveniles expressed by the binomial (B) and beta-binomial (BB) distribution of the absolute number of juveniles in the population, respectively

\begin{tabular}{|c|c|c|}
\hline $\begin{array}{l}\text { Model } \\
\text { number }\end{array}$ & Type & Model \\
\hline 1 & $\mathrm{~B}$ & Intercept \\
\hline 2 & $\mathrm{~B}$ & May average thaw days \\
\hline 3 & $\mathrm{~B}$ & May average sum \\
\hline 4 & B & Winter NAO \\
\hline 5 & B & Prior breeding population \\
\hline 6 & $\mathrm{~B}$ & $\begin{array}{l}\text { May average thaw days }+ \text { prior breeding } \\
\text { population }\end{array}$ \\
\hline 7 & $\mathrm{~B}$ & $\begin{array}{l}\text { May average thaw days } \times \text { prior breeding } \\
\text { population }\end{array}$ \\
\hline 8 & B & May average sum + prior breeding population \\
\hline 9 & B & May average sum $\times$ prior breeding population \\
\hline 10 & B & Winter NAO + prior breeding population \\
\hline 11 & B & Winter NAO $\times$ prior breeding population \\
\hline 12 & B & Snow cover \\
\hline 13 & $\mathrm{~B}$ & Snow cover + prior breeding population \\
\hline 14 & $\mathrm{~B}$ & Snow cover $\times$ prior breeding population \\
\hline 15 & BB & Intercept \\
\hline 16 & $\mathrm{BB}$ & May average thaw days \\
\hline 17 & $\mathrm{BB}$ & May average sum \\
\hline 18 & $\mathrm{BB}$ & Winter NAO \\
\hline 19 & $\mathrm{BB}$ & Prior breeding population \\
\hline 20 & BB & $\begin{array}{l}\text { May average thaw days }+ \text { prior breeding } \\
\text { population }\end{array}$ \\
\hline 21 & BB & $\begin{array}{l}\text { May average thaw days } \times \text { prior breeding } \\
\text { population }\end{array}$ \\
\hline 22 & BB & May average sum + prior breeding population \\
\hline 23 & BB & May average sum $\times$ prior breeding population \\
\hline 24 & BB & Winter NAO + prior breeding population \\
\hline 25 & BB & Winter NAO $\times$ prior breeding population \\
\hline 26 & BB & Snow cover \\
\hline 27 & BB & Snow cover + prior breeding population \\
\hline 28 & BB & Snow cover $\times$ prior breeding population \\
\hline
\end{tabular}

The top three candidate models, accounting for $53.5 \%$ of the AIC weight, were $\left(3 \mathrm{a} . R^{2}=0.1669, F_{2,28}=2.804\right.$, $p=0.0776$; 3b. $R^{2}=0.1144, F_{2,29}=3.75, p=0.0628$; 3c. $\left.R^{2}=0.1542, F_{2,28}=2.551, p=0.0960\right)$ :

$$
\begin{aligned}
p_{t} & = \\
& \frac{1}{\left(1+\exp \left(-\left(-1.4026-0.0861 \text { winter } \mathrm{NAO}_{t}-0.0094 A_{t-1}\right)\right)\right)} \\
p_{t} & =\frac{1}{\left(1+\exp \left(-\left(-1.72994-0.0675 \text { winter } \mathrm{NAO}_{t}\right)\right)\right)} \\
p_{t} & = \\
& \frac{1}{\left(1+\exp \left(-\left(-1.6874+0.0482 \text { Thaw days }_{t}-0.0142 A_{t-1}\right)\right)\right)}
\end{aligned}
$$

To expand on the indications of a change in population dynamics from a density-dependent situation between 1981 and 1999 to a density-independent situation hereafter, a piecewise regression was used to identify the point in time when the slope in productivity was no longer negative (Neter et al. 1996). Since our results indicate a change in slope after 1999, we used the years around this point to make a piecewise regression for every breakpoint between 1996 and 2004, hereafter referred to as model set 3 (Table 4). A prior model 3c, including prior adult population and the number of thaw days in May, was chosen as the candidate model. We choose the variable May thaw days over winter NAO due to several reasons. Besides having equally low AIC values and almost equal model weight, the data for May thaw days are easy accessible on June 1, are easy to interpret, and are a local and therefore a more direct measure of the snow conditions on the breeding grounds. Thus, to test the effect of adult population on the proportion of juveniles $\left(p_{t}\right)$, we fit the model (Eq. 4):

$$
p_{t}=\frac{1}{\left(1+\exp \left(-\left(\beta_{0}+\beta_{1} \text { Thaw days } t+\beta_{2} A_{t-1}+\beta_{3} \text { Index }+\beta_{4} \text { Index } \times A_{t-1}\right)\right)\right)}
$$

$95 \%$ CI $-0.0221-0.0033 ; 3 \mathrm{c} . \beta_{\mathrm{z}}=-0.0142,95 \% \mathrm{CI}$ $-0.0285-0.0001)$.

In regards to the climatic variables in the three models, the winter NAO index had a negative effect on the proportion of juveniles, with high values in NAO index associated with small proportions of juveniles. May thaw days have a positive effect on the proportion of juveniles. where index $=0$ for years in the first time segment and 1 otherwise.

Given the set of candidate models for the period 19962004 (Table 4), the model with a breakpoint after 1998 (Eq. 5a, 5b) had the lowest AIC value and the highest model weight (0.2305), compared to the second best model with a breakpoint after 1999 (dAIC 0.8, weight 0.1573) 
2000-2011
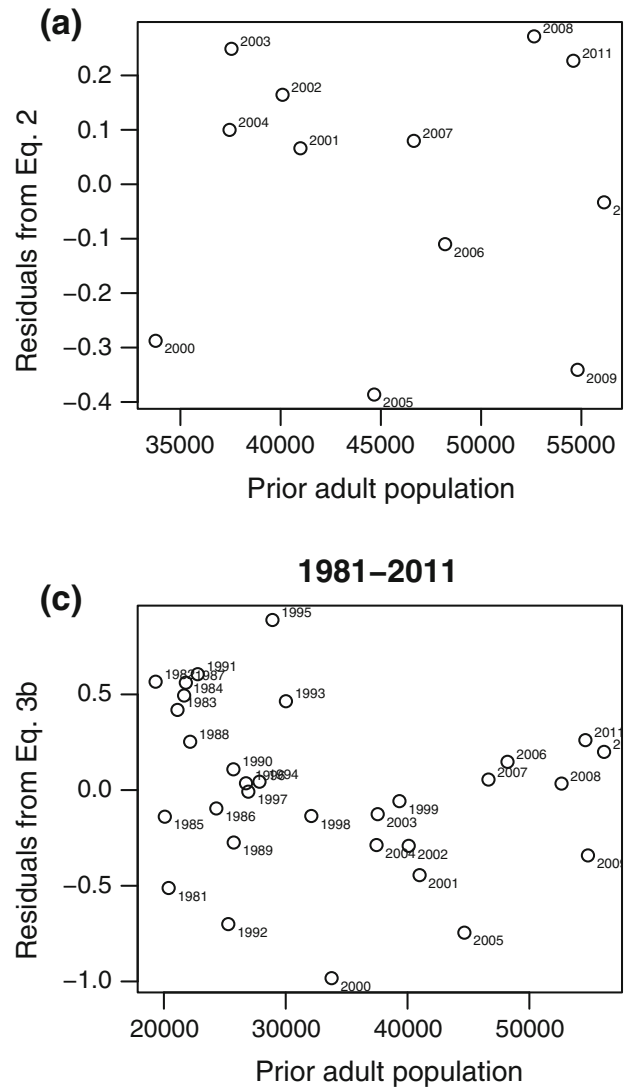

1981-2011

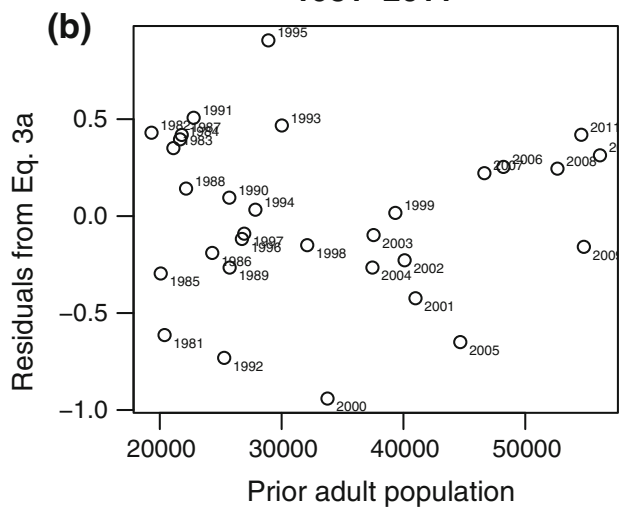

1981-2011

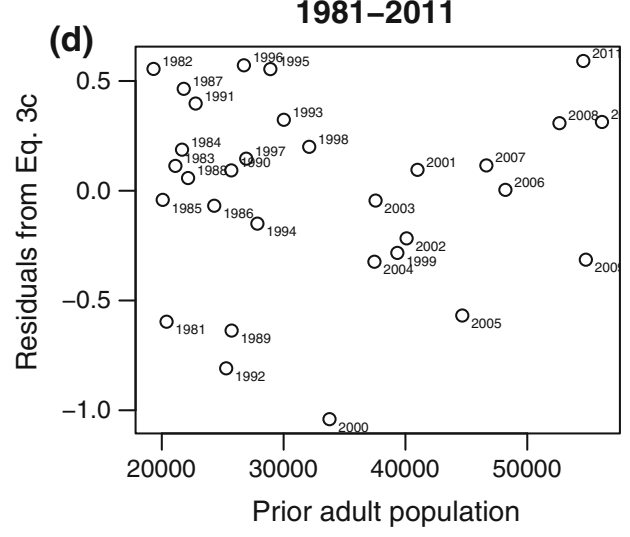

Fig. 6 Residual plots for (a) the best candidate model from model set 1, and (b, c, d) the top three candidate models from model set 2

(Table 5). The best candidate model was, for segment 1 and 2, respectively:

$$
\begin{aligned}
& p_{t,<1999}= \\
& \frac{1}{\left(1+\exp \left(-\left(-1.8609+0.0434 \text { Thaw days }_{t}-0.0036 A_{t-1}\right)\right)\right)}
\end{aligned}
$$

$$
\begin{aligned}
& p_{t,>1998}= \\
& \frac{1}{\left(1+\exp \left(-\left(-3.2863+0.0434 \text { Thaw days }_{t}+0.0201 A_{t-1}\right)\right)\right)}
\end{aligned}
$$

The piecewise regression suggests a release from density-dependent reproduction, but there is still no statistical evidence of either a negative or positive effect from adult population size on the proportion of juveniles (5a. $\beta_{4}=-0.0036, \quad 95 \%$ CI $-0.0405-0.0550 ; 5$ b. $\beta_{4}=0.0201,95 \%$ CI $\left.-0.0385-0.0786\right)$. However, a likelihood ratio test for model selection between the piecewise regression model using breakpoint 1998 and a model with a constant slope strongly suggests that the piecemeal slope is a better model than the model with a constant slope $(P=0.0230)$.

\section{Discussion}

Selection of climate variables as proxy for breeding output

The aim of this paper was to find a general climatic predictor for the breeding output of the Svalbard population of pinkfooted geese, to be used in a predictive model to optimize the harvest of the population. This will allow authorities to regulate harvest based on climate as a proxy for breeding output. Our results show that for the most recent decade, the proportion of juveniles, used as an expression of the overall productivity of Svalbard pink-footed geese, can be predicted from snow cover at local nesting sites, derived from MODIS satellite images. Prior to 2000, when snow cover estimates are not available, the results are not as clear and both winter NAO and the May thaw days can be used as predictors. It should be borne in mind that the above-mentioned predictors only provide proxies of the annual breeding output in Arcticnesting geese, and much of the variability in breeding success remains unexplained.

We suggest snow cover or May thaw days are the most suitable environmental variables to include in predictive 
Table 2 AIC values for model set 1 (time series 2000-2011), using explanatory variables

\begin{tabular}{|c|c|c|c|c|c|c|c|c|c|c|c|c|}
\hline Model & $\begin{array}{l}\text { Model } \\
\text { number }\end{array}$ & Type & AIC & $d f$ & dAIC & $\begin{array}{l}\text { AIC } \\
\text { weight }\end{array}$ & $\begin{array}{l}\text { Model } \\
\text { number }\end{array}$ & Type & AIC & $d f$ & $\mathrm{dAIC}$ & $\begin{array}{l}\text { AIC } \\
\text { weight }\end{array}$ \\
\hline $\begin{array}{l}\text { Snow cover }+ \text { prior breeding } \\
\text { population }\end{array}$ & 27 & $\mathrm{BB}$ & 215.1 & 4 & 0 & 0.44004 & 13 & B & 3278.4 & 3 & $3,063.3$ & $<0.001$ \\
\hline Snow cover & 26 & $\mathrm{BB}$ & 217.3 & 3 & 2.2 & 0.1462 & 12 & B & 6329.1 & 2 & 6,114 & $<0.001$ \\
\hline $\begin{array}{l}\text { Winter NAO }+ \text { prior breeding } \\
\text { population }\end{array}$ & 24 & $\mathrm{BB}$ & 218.1 & 4 & 3 & 0.09951 & 10 & B & 4703.9 & 3 & $4,488.8$ & $<0.001$ \\
\hline $\begin{array}{l}\text { Snow cover } \times \text { prior breeding } \\
\text { population }\end{array}$ & 28 & $\mathrm{BB}$ & 218.3 & 5 & 3.2 & 0.0897 & 14 & B & 5438.6 & 4 & $5,223.5$ & $<0.001$ \\
\hline $\begin{array}{l}\text { May average sum }+ \text { prior breeding } \\
\text { population }\end{array}$ & 22 & BB & 219.3 & 4 & 4.2 & 0.05311 & 8 & B & 5415.1 & 3 & 5,200 & $<0.001$ \\
\hline $\begin{array}{l}\text { Winter NAO } \times \text { prior breeding } \\
\text { population }\end{array}$ & 25 & $\mathrm{BB}$ & 220 & 5 & 4.9 & 0.03879 & 11 & B & 4712.7 & 4 & 4,497.6 & $<0.001$ \\
\hline Prior breeding population & 19 & BB & 220 & 3 & 4.9 & 0.0387 & 5 & B & 6871.1 & 2 & 6,656 & $<0.001$ \\
\hline Winter NAO & 18 & BB & 220.1 & 3 & 5 & 0.03679 & 4 & B & 7027.8 & 2 & $6,812.7$ & $<0.001$ \\
\hline $\begin{array}{l}\text { May average thaw days }+ \text { prior } \\
\text { breeding population }\end{array}$ & 20 & $\mathrm{BB}$ & 220.3 & 4 & 5.2 & 0.0334 & 6 & B & 5850.5 & 3 & $5,635.4$ & $<0.001$ \\
\hline May average thaw days & 16 & $\mathrm{BB}$ & 222.1 & 3 & 7 & 0.01358 & 2 & B & 8596.5 & 2 & $8,381.4$ & $<0.001$ \\
\hline May average sum & 17 & BB & 223.5 & 3 & 8.4 & 0.00658 & 3 & B & 9639.5 & 2 & $9,424.4$ & $<0.001$ \\
\hline Intercept & 15 & $\mathrm{BB}$ & 225.5 & 2 & 10.4 & 0.00244 & 1 & B & 13527.2 & 1 & $13,312.1$ & $<0.001$ \\
\hline $\begin{array}{l}\text { May average thaw days } \times \text { prior } \\
\text { breeding population }\end{array}$ & 21 & $\mathrm{BB}$ & 227 & 5 & 11.9 & 0.00116 & 7 & B & 24757.8 & 4 & $24,542.7$ & $<0.001$ \\
\hline $\begin{array}{l}\text { May average sum } \times \text { prior breeding } \\
\text { population }\end{array}$ & 23 & BB & 258.1 & 5 & 43 & $<0.001$ & 9 & B & 5415.1 & 3 & 5.200 & $<0.001$ \\
\hline
\end{tabular}

Table 3 AIC values for model set 2 (time series 1981-2011), using explanatory variables

\begin{tabular}{|c|c|c|c|c|c|}
\hline Model & Model number & AIC & $d f$ & dAIC & AIC weight \\
\hline Winter NAO + prior breeding population & 24 & 558.929 & 4 & 0 & 0.1791 \\
\hline Winter NAO & 18 & 558.931 & 3 & 0 & 0.1787 \\
\hline May average thaw days + prior breeding population & 20 & 558.946 & 4 & 0 & 0.1774 \\
\hline Winter NAO $\times$ prior breeding population & 25 & 560.1 & 5 & 1.2 & 0.0993 \\
\hline May average thaw days & 16 & 560.2 & 3 & 1.3 & 0.0934 \\
\hline May average sum + prior breeding population & 22 & 560.3 & 4 & 1.4 & 0.0908 \\
\hline May average sum & 17 & 560.3 & 3 & 1.4 & 0.0905 \\
\hline Intercept & 15 & 561 & 2 & 2.1 & 0.0642 \\
\hline Prior breeding population & 19 & 562.7 & 3 & 3.8 & 0.0267 \\
\hline May average thaw days $\times$ prior breeding population & 21 & 595.2 & 5 & 36.3 & $<0.001$ \\
\hline May average sum $\times$ prior breeding population & 23 & 602.7 & 5 & 43.7 & $<0.001$ \\
\hline Winter NAO $\times$ prior breeding population & 11 & $20,653.4$ & 4 & 20094.5 & $<0.001$ \\
\hline Winter NAO + prior breeding population & 10 & $21,865.4$ & 3 & 21306.5 & $<0.001$ \\
\hline May average thaw days + prior breeding population & 6 & $21,972.3$ & 3 & 21413.4 & $<0.001$ \\
\hline Winter NAO & 4 & $22,830.6$ & 2 & 22271.7 & $<0.001$ \\
\hline May average sum + prior breeding population & 8 & $22,894.3$ & 3 & 22335.3 & $<0.001$ \\
\hline May average sum $\times$ prior breeding population & 9 & $22,894.3$ & 3 & 22335.3 & $<0.001$ \\
\hline May average thaw days & 2 & $23,554.5$ & 2 & 22995.6 & $<0.001$ \\
\hline May average sum & 3 & $23,696.9$ & 2 & 23138 & $<0.001$ \\
\hline Intercept & 1 & $26,628.4$ & 1 & 26069.5 & $<0.001$ \\
\hline Prior breeding population & 5 & $26,630.2$ & 2 & 26071.3 & $<0.001$ \\
\hline May average thaw days $\times$ prior breeding population & 7 & $30,149.6$ & 4 & 29590.7 & $<0.001$ \\
\hline
\end{tabular}


Table 4 Candidate models of the relationship between the number of thaw days in May + prior adult population and the proportion of juveniles expressed by a model with a constant slope for density dependence between 1981-2011 and a range of models with a different slope for density dependence post years between 1996 and 2004

\begin{tabular}{ll}
\hline Model number & Model \\
\hline 1 & $1981-1996,1997-2011$ \\
2 & $1981-1997,1998-2011$ \\
3 & $1981-1998,1999-2011$ \\
4 & $1981-1999,2000-2011$ \\
5 & $1981-2000,2001-2011$ \\
6 & $1981-2001,2002-2011$ \\
7 & $1981-2002,2003-2011$ \\
8 & $1981-2003,2004-2011$ \\
9 & $1981-2004,2005-2011$ \\
10 & $1981-2011$ \\
\hline
\end{tabular}

Table 5 AIC values for model set 3 (May average thaw days + prior breeding population), using a model with a constant slope for density dependence between 1981-2011 and a range of models with a different slope for density dependence post years between 1996 and 2004

\begin{tabular}{lcclll}
\hline Model & $\begin{array}{l}\text { Model } \\
\text { number }\end{array}$ & AIC & $d f$ & dAIC & $\begin{array}{l}\text { AIC } \\
\text { weight }\end{array}$ \\
\hline 1981-1998, 1999-2011 & 3 & 555.4 & 6 & 0 & 0.3360 \\
$1981-1999,2000-2011$ & 4 & 556.2 & 6 & 0.8 & 0.2292 \\
$1981-1997,1998-2011$ & 2 & 557.7 & 6 & 2.3 & 0.1050 \\
$1981-2011$ & 10 & 558.9 & 4 & 3.5 & 0.0572 \\
$1981-2004,2005-2011$ & 9 & 559.1 & 6 & 3.7 & 0.0523 \\
$1981-2003,2004-2011$ & 8 & 559.2 & 6 & 3.8 & 0.0509 \\
$1981-2000,2001-2011$ & 5 & 559.2 & 6 & 3.8 & 0.0492 \\
$1981-2001,2002-2011$ & 6 & 559.6 & 6 & 4.2 & 0.0418 \\
$1981-2002,2003-2011$ & 7 & 559.6 & 6 & 4.2 & 0.0418 \\
$1981-1996,1997-2011$ & 1 & 559.8 & 6 & 4.4 & 0.0365 \\
\hline
\end{tabular}

population models. Snow cover is a direct measure of the snow conditions on the breeding grounds and has higher explanatory power than May thaw days. However, due to lack of snow cover data pre-2000, May thaw days have an advantage. In addition, classification of MODIS satellite images can only be done on cloud-free images and optimally around midday when the sun is highest, since shadows will affect the classification results. This is in contrast to May thaw days which is easy accessible on June 1.

We also suggest May thaw days over winter NAO. Besides having equally low AIC values and almost equal model weight, the data for May thaw days are a local and therefore a more direct measure of the snow conditions on the breeding grounds. Further, May thaw days is easy to interpret in contrast to NAO. NAO makes predictions for two variables, temperature and precipitation, with low NAO predicting a warm and wet year and a high NAO predicting a cold and dry year (Svalbard being opposite to the normal interpretation of NAO on European weather patterns). These predictions have opposing effects on the production of juveniles, with a warm year being associated with a high productivity and a wet year being associated with a low productivity. This contradiction makes the interpretation of NAO difficult. However, sporadic snow depth measurements from Longyearbyen indicate a general low snow depth $(<60 \mathrm{~cm})$, which means that precipitation may have little influence in the timing of snow clearance compared to temperatures and hence on the prediction of productivity.

For now, we do not recommend using the annual SMO estimates. Besides on the lack of data from 2009 onward, annual SMO has other limitations. At present, the annual SMO is estimated from large regional glacier-covered areas in contrast to the snow cover analyses, which are derived from local nesting sites, i.e., it gives a more direct estimate of nest-site availability. However, a positive argument for using SMO is the ability of satellite radars to obtain data independent of daylight and cloud cover, which is in contrast to the snow cover classification of MODIS satellite images.

\section{Ecological implications of warming}

The most surprising difference found between the shortand the long-time series was the indication of change in population dynamics from a density-dependent situation during 1981-1998 to a density-independent situation thereafter. Given the observed level shift in our environmental variables toward warmer weather and less snow in May from 2000 onward, this is consistent with a hypothesis of released breeding potential due to climate change.

To our knowledge, this is one of the first studies to suggest that an Arctic population has escaped density dependence with climate change. The findings support the predictions that even subtle increases in spring and summer temperatures will increase the suitable breeding area for pink-footed geese in Svalbard (Jensen et al. 2008). The predictions were based on nest-distribution data collected prior to 2006 (most data stem from before 2000), and as temperature data have shown, there has been an almost doubling in thaw days in May from before to after 2000.

As discussed in Madsen et al. (2007), snow cover may affect goose breeding performance in numerous ways, directly by affecting availability of nest sites on arrival and indirectly by affecting feeding opportunities during prenesting and incubation. If snow melt is delayed, many pairs of geese abandon nesting attempts, and for pairs which 
nest, the likelihood of being successful decreases. In this analysis, the tendency is still toward a higher productivity in years with less snow cover, and in addition to the previous analysis, it has also been shown that a high May temperature sum or more May thaw days and a lower winter NAO index relate to higher productivity. In the Sassendalen study area, the number of nests can vary fivefold between early and late years and has been more than doubled during 2003-2012 (Madsen et al. 2007; Anderson et al. submitted), suggesting that the population has not exhausted food resources, but instead is controlled by factors like nest-site availability. Hence, if a barrier like snow cover is not present, a large pool of goose pairs which are capable of reproducing can start nesting and have a good chance of success. This could result in a higher carrying capacity, and we suggest this is one of the main mechanisms behind the recent increase in population productivity, which has contributed to the observed population growth.

In this paper, we have shown that various climatic variables in the spring can be used to predict the overall productivity of pink-footed geese. The same conclusions were made by Morrissette et al. (2010), who examined the effect of selected environmental variables on the population productivity of greater snow geese Anser caerulescens atlanticus. They too found that spring climatic conditions in the Canadian Arctic were the most dominant factor affecting goose breeding productivity, probably a result of snow cover affecting nest propensity. However, reproduction success (as measured during fall) is influenced by conditions encountered over a longer period. Other direct and indirect climatic conditions on the breeding grounds having an effect on reproductive success include the following: (A) precipitation during early summer, where high precipitation increases water availability and allows females to stay closer to their nest during incubation; this may result in a reduction in egg predation rate (Dickey et al. 2008; Lecomte et al. 2009); (B) temperature during mid-summer, where high temperatures increase gosling survival and growth by decreasing costs of thermoregulation, reduces exposure to cold temperatures, and increases the availability of food (Dickey et al. 2008); (C) earlier snow melt and elevated summer temperatures may advance the growth of forage plants, leading to a mismatch between time of hatching of goslings and time for peak plant nutrient content, ultimately impacting gosling growth and survival (Gauthier et al. 2013); (D) temperatures during late summer and fall, where high temperatures have a positive effect on juvenile survival by extending the period of food availability (Menu et al. 2005); (E) warming and extreme events may alter interactions between geese and their predators in unpredictable ways; in Svalbard, the main predators are Arctic fox Vulpes alopex (adults as well as eggs), gulls, and skuas (eggs only). Hansen et al. (2013) have shown that extreme weather events (rain on snow causing icing) synchronize population fluctuations across an entire community of resident vertebrate herbivores and cause lagged correlations with the secondary consumer, the arctic fox. This may also cause a higher fox predation pressure on geese, and we might see the first signs of this in local colonies (Anderson et al. submitted). Further, polar bears Ursus maritimus increasingly occur on the west coast of Svalbard in summer, possibly due to decreasing sea ice conditions. Bears prey on eggs in bird colonies, and the island nesting barnacle goose Branta leucopsis has been suffering severe nest losses resulting in a decline in goose numbers in the coastal areas (Drent and Prop 2008). In recent years, bears have also moved further inland and have depredated local pink-footed goose nests (Prop unpubl. data). So far, we did not record signs of polar bear predation in the interior fjord colonies such as Sassendalen.

The above-mentioned factors (A-E) will positively or negatively impact the population dynamics of the Arctic goose population; for the moment, we are not able to evaluate their relative importance. Further, we have not included any possible carry-over effects of weather conditions, food availability, and management of habitats on the spring staging grounds which may affect body reserves and, ultimately, breeding success of Arctic-nesting geese (Ebbinge and Spaans 1995; Mainguy et al. 2002; Klaassen et al. 2006)

\section{Perspectives}

Our results provide insights into the kind of population dynamic that can be expected with a warmer climate. We predict that with a climate-induced decrease in snow cover in Svalbard, the population of pink-footed geese will increase its growth, at least in the short term. This will most likely result in an escalation of agricultural conflicts along the migration route and an increase in tundra degradation. Whether increased harvest levels will be able to stabilize the population remains to be seen. Built into the adaptive process is the recurrent tuning of predictive models, and it will be important to gain a better understanding of how and where in time, climate will affect future population processes.

Acknowledgments This study was financed by the Norwegian Research Council (project GOOSEHUNT) and Aarhus University. We thank Fred Cottaar for contributing with age counts of geese. Frank Rigét and Mads C. Forchhammer are thanked for providing input to the paper. Funding for this research was also provided by the U.S. Geological Survey. Any use of trade, product, or firm names in this article is for descriptive purposes only and does not imply endorsement by the U.S. Government. 
Open Access This article is distributed under the terms of the Creative Commons Attribution License which permits any use, distribution, and reproduction in any medium, provided the original author(s) and the source are credited.

\section{References}

ACIA (2005) Arctic tundra and polar desert ecosystems. Arctic climate impact assessment. Cambridge University Press, Cambridge

AMAP (2011) Snow, water, ice and permafrost in the arctic (SWIPA): climate change and the cryosphere. arctic monitoring and assessment programme (AMAP). Oslo

Bamzai AS (2003) Relationship between snow cover variability and arctic oscillation index on a hierarchy of time scales. Int $\mathrm{J}$ Climatol 23:131-142

Burnham KP, Anderson DR (2002) Model selection and multimodel inference: a practical information-theoretic approach. Springer Science, New York

Cadieux MC, Gauthier G, Gagnon CA, Bêty J, Berteaux D (2008) Monitoring the environmental and ecological impacts of climate change on Bylot Island, Sirmilik National Park. Université Laval, Quebec

Cleveland WS (1979) Robust locally weighted regression and smoothing scatterplots. J Am Stat Assoc 74:829-836

Dickey MH, Gauthier G, Cadieux MC (2008) Climatic effects on the breeding phenology and reproductive success of an arcticnesting goose species. Glob Change Biol 14:1973-1985

Drent RH, Prop J (2008) Barnacle goose Branta leucopsis survey on Nordenskiöldkysten, West Spitsbergen 1975-2007: breeding in relation to carrying capacity and predator impact. Circumpolar Stud 4:59-83

Drent R, Both C, Green M, Madsen J, Piersma T (2003) Pay-offs and penalties of competing migratory schedules. Oikos 103:274-292

Ebbinge B, Spaans B (1995) The importance of body reserves accumulated in spring staging areas in the temperate zone for breeding in dark-bellied brent geese Branta b. bernicla in the High Arctic. J Avian Biol 26:105-113

Ganter B, Madsen J (2001) An examination of methods to estimate population size in wintering geese. Bird Study 48:90-101

Gauthier G, Bêty J, Cadieux M, Legagneux P, Doiron M, Chevallier C, Lai S, Tarroux A, Berteaux D (2013) Long-term monitoring at multiple trophic levels suggests heterogeneity in responses to climate change in the Canadian Arctic tundra. Phil Trans R Soc B 368

Gilg O, Kovacs KM, Aars J, Fort J, Gauthier G, Grémillet D, Ims RA, Meltofte H, Moreau J, Post E, Schmidt NM, Yannic G, Bollache L (2012) Climate change and the ecology and evolution of Arctic vertebrates. Ann N Y Acad Sci 1249:166-190

Glahder CM, Fox TA, Hubner CE, Madsen J, Tombre IM (2006) Prenesting site use of satellite transmitter tagged Svalbard pinkfooted geese Anser brachyrhynchus. Ardea 94:679-690

Glahder CM, Fox AD, O'Connell M, Jespersen M, Madsen J (2007) Eastward moult migration of non-breeding pink-footed geese Anser brachyrhynchus in Svalbard. Polar Res 26:31-36

Hansen B, Grøtan V, Aanes R, Sæther B, Stien A, Fuglei E, Ims R, Yoccoz N, Pedersen A (2013) Climate events synchronize the dynamics of a resident vertebrate community in the high Arctic. Science 339:313-315

Hurrell JW (1995) Decadal trends in the North-Atlantic oscillationregional temperatures and precipitation. Science 269:676-679

Hurrell JW (1996) Influence of variations in extratropical wintertime teleconnections on Northern Hemisphere temperature. Geophys Res Lett 23:665-668
Jensen RA, Madsen J, O'Connell M, Wisz MS, Tommervik H, Mehlum F (2008) Prediction of the distribution of Arctic-nesting pink-footed geese under a warmer climate scenario. Glob Change Biol 14:1-10

Klaassen M, Bauer S, Madsen J, Ingunn T (2006) Modelling behavioural and fitness consequences of disturbance for geese along their spring flyway. J Appl Ecol 43:92-100

Lecomte N, Gauthier G, Giroux JF (2009) A link between water availability and nesting success mediated by predator-prey interactions in the Arctic. Ecology 90:465-475

Lepage D, Gauthier G, Menu S (2000) Reproductive consequences of egg-laying decisions in snow geese. J Anim Ecol 69:414-427

Luks B, Osuch M, Romanowicz RJ (2011) The relationship between snowpack dynamics and NAO/AO indices in SW Spitsbergen. Phys Chem Earth 36:646-654

Madsen J, Williams JH (2012) International species management plan for the Svalbard population of the pink-footed goose Anser brachyrhynchus. AEWA Technical Series., vol 48. Bonn, Germany

Madsen J, Tamstorf M, Klaassen M, Eide N, Glahder C, Riget F, Nyegaard H, Cottaar F (2007) Effects of snow cover on the timing and success of reproduction in high-Arctic pink-footed geese Anser brachyrhynchus. Polar Biol 30:1363-1372

Madsen J, Jaspers C, Tamstorf M, Mortensen C, Rigét F (2011) Longterm effects of grazing and global warming on the composition and carrying capacity of graminoid marshes for moulting geese in East Greenland. AMBIO. J Hum Environ 40:638-649

Mainguy J, Bety J, Gauthier G, Giroux JF (2002) Are body condition and reproductive effort of laying greater snow geese affected by the spring hunt? Condor 104:156-161

Menu S, Gauthier G, Reed A (2005) Survival of young greater snow geese Chen caerulescens atlantica during fall migration. Auk 122:479-496

Morrissette M, Bety J, Gauthier G, Reed A, Lefebvre J (2010) Climate, trophic interactions, density dependence and carry-over effects on the population productivity of a migratory Arctic herbivorous bird. Oikos 119:1181-1191

Neter J, Kutner MH, Nachtsheim CJ, Wasserman W (1996) Applied linear statistical models. WCB/McGraw Hill, Boston

Nichols J, Runge M, Johnson F, Williams B (2007) Adaptive harvest management of North American waterfowl populations: a brief history and future prospects. J Ornithol 148:343-349

Owen M (1980) Wild geese of the world. Batsford, London

Owen M, Norderhaug M (1977) Population dynamics of barnacle geese Branta leucopsis breeding in Svalbard, 1948-1976. Ornis Scand 8:161-174

Patterson IJ, Hearn RD (2006) Month to month changes in age ratio and brood size in pink-footed geese Anser brachyrhynchus in autumn. Ardea 94:175-183

Post E, Pedersen C, Wilmers CC, Forchhammer MC (2008) Warming, plant phenology and the spatial dimension of trophic mismatch for large herbivores. Proc Roy Soc B Biol Sci 275:2005-2013

Post E, Forchhammer MC, Bret-Harte MS, Callaghan TV, Christensen TR, Elberling B, Fox AD, Gilg O, Hik DS, Hoye TT, Ims RA, Jeppesen E, Klein DR, Madsen J, McGuire AD, Rysgaard S, Schindler DE, Stirling I, Tamstorf MP, Tyler NJC, van der Wal R, Welker J, Wookey PA, Schmidt NM, Aastrup P (2009) Ecological dynamics across the arctic associated with recent climate change. Science 325:1355-1358

Prop J, de Vries J (1993) Impact of snow and food conditions on the reproductive performance of barnacle geese Branta leucopsis. Ornis Scand 24:110-121

Reeves HM, Cooch FG, Munro RE (1976) Monitoring arctic habitat and goose production by satellite imagery. J Wildl Manag 40:532-541 
Rotschky G, Schuler TV, Haarpaintner J, Kohler J, Isaksson E (2011) Spatio-temporal variability of snowmelt across Svalbard during the period 2000-08 derived from QuikSCAT/SeaWinds scatterometry. Polar Res 30

Speed JDM, Woodin SJ, Tommervik H, Tamstorf MP, van der Wal R (2009) Predicting habitat utilization and extent of ecosystem disturbance by an increasing herbivore population. Ecosystems 12:349-359

Strong LL, Trost RE (1994) Forecasting production of arctic nesting geese by monitoring snow cover with advanced very high resolution radiometer (AVHRR) data. In: proceedings of the
Pecora symposium Jamestown, 1994. vol 12. Northern Prairie Wildlife Research Center Online, 425-430

Tyler NJC, Forchhammer MC, Oritsland NA (2008) Nonlinear effects of climate and density in the dynamics of a fluctuating population of reindeer. Ecology 89:1675-1686

Wisz M, Dendoncker N, Madsen J, Rounsevell M, Jespersen M, Kuijken E, Courtens W, Verscheure C, Cottaar F (2008) Modelling pink-footed goose Anser brachyrhynchus wintering distributions for the year 2050: potential effects of land-use change in Europe. Divers Distrib 14:721-731 